\title{
Complement peptide C3a receptor 1 promotes optic nerve degeneration in DBA/2J mice
}

Jeffrey M. Harder ${ }^{1}$, Pete A. Williams ${ }^{1,2} \mathbb{B}$, Catherine E. Braine ${ }^{1,3}$, Hongtian S. Yang ${ }^{1}$, Jocelyn M. Thomas', Nicole E. Foxworth', Simon W. M. John ${ }^{1,4,5^{*}}$ and Gareth R. Howell ${ }^{1,6,7^{*}}$ (i)

\begin{abstract}
Background: The risk of glaucoma increases significantly with age and exposure to elevated intraocular pressure, two factors linked with neuroinflammation. The complement cascade is a complex immune process with many bioactive end-products, including mediators of inflammation. Complement cascade activation has been shown in glaucoma patients and models of glaucoma. However, the function of complement-mediated inflammation in glaucoma is largely untested. Here, the complement peptide C3a receptor 1 was genetically disrupted in DBA/2J mice, an ocular hypertensive model of glaucoma, to test its contribution to neurodegeneration.
\end{abstract}

Methods: A null allele of C3ar1 was backcrossed into DBA/2J mice. Development of iris disease, ocular hypertension, optic nerve degeneration, retinal ganglion cell activity, loss of RGCs, and myeloid cell infiltration in C3ar1-deficient and sufficient DBA/2J mice were compared across multiple ages. RNA sequencing was performed on microglia from primary culture to determine global effects of C3arl on microglia gene expression.

Results: Deficiency in C3arl lowered the risk of degeneration in ocular hypertensive mice without affecting intraocular pressure elevation at 10.5 months of age. Differences were found in the percentage of mice affected, but not in individual characteristics of disease progression. The protective effect of C3ar1 deficiency was then overcome by additional aging and ocular hypertensive injury. Microglia and other myeloid-derived cells were the primary cells identified that express C3ar1. In the absence of C3ar1, microglial expression of genes associated with neuroinflammation and other immune functions were differentially expressed compared to WT. A network analysis of these data suggested that the IL10 signaling pathway is a major interaction partner of C3AR1 signaling in microglia.

Conclusions: C3AR1 was identified as a damaging neuroinflammatory factor. These data help suggest complement activation causes glaucomatous neurodegeneration through multiple mechanisms, including inflammation. Microglia and infiltrating myeloid cells expressed high levels of C3ar1 and are the primary candidates to mediate its effects. C3AR1 appeared to be a major regulator of microglia reactivity and neuroinflammatory function due to its interaction with IL10 signaling and other immune related pathways. Targeting myeloid-derived cells and C3AR1 signaling with therapies is expected to add to or improve neuroprotective therapeutic strategies.

Keywords: Glaucoma, Complement, Anaphylatoxin, Microglia, Monocytes, Neurodegeneration

\footnotetext{
* Correspondence: sj2967@cumc.columbia.edu; gareth.howell@jax.org

${ }^{1}$ The Jackson Laboratory, Bar Harbor, ME, USA

Full list of author information is available at the end of the article
}

(C) The Author(s). 2020 Open Access This article is licensed under a Creative Commons Attribution 4.0 International License, which permits use, sharing, adaptation, distribution and reproduction in any medium or format, as long as you give appropriate credit to the original author(s) and the source, provide a link to the Creative Commons licence, and indicate if changes were made. The images or other third party material in this article are included in the article's Creative Commons licence, unless indicated otherwise in a credit line to the material. If material is not included in the article's Creative Commons licence and your intended use is not permitted by statutory regulation or exceeds the permitted use, you will need to obtain permission directly from the copyright holder. To view a copy of this licence, visit http://creativecommons.org/licenses/by/4.0/ The Creative Commons Public Domain Dedication waiver (http://creativecommons.org/publicdomain/zero/1.0/) applies to the data made available in this article, unless otherwise stated in a credit line to the data. 


\section{Introduction}

Glaucoma is a common disease that damages the optic nerve and impairs vision [1]. Risk for glaucoma is greatly increased after middle age and by exposure to elevated intraocular pressure (IOP). Elevated IOP and aging are associated with neuroinflammation, yet it remains unclear when and how neuroinflammation becomes damaging in glaucoma and how to intervene [2, 3]. These questions underlie a need to develop a comprehensive understanding of inflammatory processes in glaucoma.

A major type of inflammatory response observed in glaucoma patients is activation of the complement cascade [4-6]. The complement cascade is activated by three distinct pathways, the classical, alternative, and mannose-binding lectin pathways, which play a key role in responding to tissue damage and infection. The final product of the complement cascade, the membrane attack complex (MAC), has been identified in optic nerve tissue from ocular hypertensive patients. This suggests full activation of the complement cascade has occurred, including multiple steps that promote neuroinflammation. The major products of the complement cascade that regulate neuroinflammation are complement activation peptides and the MAC [7, 8]. The two primary complement activation peptides are polypeptides produced by the cleavage of complement components 3 and 5, and named C3a and C5a. C3a and C5a bind to different cell surface $G$ protein coupled receptors, C3AR1 and C5AR1, respectively. Both receptors can be expressed by glia, neurons, and infiltrating immune cells in the central nervous system. However, whereas C5AR1 largely promotes activation of immune cells, the outcome promoted by C3AR1 varies by the type of injury, cell, and costimulation involved in the inflammatory response [9]. The MAC is a complex formed on plasma membranes by complement components $5 \mathrm{~b}, 6,7,8$, and 9 as a result of opsonized antigens. Low levels of the MAC on target cells activate intracellular signaling pathways and high levels induce lysis. Sublytic levels of the MAC amplify inflammatory intracellular signaling pathways by activating the NFKB signaling and inflammasome pathways [10, 11 . Due to the potentially damaging role of inflammation in glaucoma and other neurodegenerative disorders, the complement activation peptides and the MAC are predicted to be useful targets for developing antiinflammatory therapies $[12,13]$.

Research in animal models suggests that the complement cascade contributes to pathology in ocular hypertensive eyes [4, 14-21]. This includes models of glaucoma like DBA/2J mice, who develop an ocular hypertensive disease in which the complement component 1q complex (C1q) or C5 exacerbates neuroinflammation, retinal ganglion cell loss and optic nerve degeneration [21-24]. These data further support the need to determine the function of pro- inflammatory products of the complement cascade after an ocular hypertensive insult. To test the function of complement activation peptide C3a in a chronic, age-related model of glaucoma, we backcrossed a null allele of the C3a receptor $\left(\mathrm{C}_{\mathrm{ar}} 1^{-}\right)$into $\mathrm{DBA} / 2 \mathrm{~J}$ mice. C3AR1 is a G-protein coupled receptor expressed in cells in the nervous and immune systems (see review: [25]) and is implicated in neuropathology in several diseases [26-30]. In DBA/2J mice, C3ar1 deficiency decreased the incidence of optic nerve damage and RGC loss at a time point consistent with C3a promoting neurodegeneration.

\section{Methods}

\section{Animals and husbandry}

C.129S4-C3ar1 ${ }^{\text {tm1Cge }} / \mathrm{J} \quad\left(\mathrm{C}_{\mathrm{arr}}{ }^{-}\right)$mice were obtained from The Jackson Laboratory (Bar Harbor, ME, USA; stock number 005712) [31]. The C3ar1 null allele was backcrossed onto DBA/2J (D2) for 10 generations to generate the congenic strain D2.129S4(C)-C3ar1 ${ }^{\text {tm1Cge }}$ / $\mathrm{Sj}$. Experimental cohorts of mice were produced by intercrossing heterozygous $\left(\mathrm{C} \mathrm{arl}^{+/-}\right)$mice. Mice of both sexes were used, with approximately equal numbers for each age group and genotype. Mice were housed with a 14-h-light/10-h-dark cycle as previously described [32]. All animals were treated according to the guidelines of the Association for Research in Vision and Ophthalmology for use of animals in research. The Animal Care and Use Committee of The Jackson Laboratory approved all experimental procedures.

\section{Clinical assessment}

Assessment of iris disease was performed using a slit-lamp biomicroscope as previously reported [33] and mice were assessed every 2 months beginning at 6 months of age. IOP was measured by the microneedle method while mice were under anesthesia (ketamine/xylazine) [34, 35]. Mice were assessed every 2 months beginning at 8 months of age. Iris disease and IOP data were collected for at least 40 eyes of each age and genotype.

\section{Optic nerve damage}

Damaged axons stain darkly when treated with the sensitive chemical marker paraphenylenediamine (PPD) [36]. We assessed optic nerve damage by staining crosssections of the retro-orbital optic nerve with PPD. Two masked investigators assigned each optic nerve one of three damage levels: no or early (NOE; no readily detectible axon loss), moderate (MOD; less than 50\% of axons damaged/lost), and severe (SEV; more than $50 \%$ of axons damaged/lost). This method of evaluating optic nerve damage has been carefully validated by counting axons [21, 37-40]. Glaucomatous axon damage was assessed in 10.5- and 12-month-old $\mathrm{C}_{3} \mathrm{arl}^{+/+}$and $\mathrm{C}^{+\mathrm{arl}^{-/-}}$mice (55 nerves for each age and genotype). 


\section{RGC soma loss}

Eyes were fixed overnight in $4 \%$ paraformaldehyde. Retinas were dissected, flat-mounted, and Nissl-stained with cresyl violet as previously described [39]. Images of $40 \times$ fields of the RGC layer were obtained using a Zeiss Axiolmager. To account for regional variation in RGC density, two $40 \times$ fields were counted in each retinal quadrant equidistant to the periphery. The counts in the eight fields were averaged to obtain a single count per eye. Eight eyes were counted per optic nerve damage level and genotype. It is important to note that the RGC layer consists of roughly $50 \%$ RGCs. This limits the extent of total neuron loss measured because only RGCs die in standard DBA/2J mice. Loss of RGCs by Nissl staining correlates well with loss of RGCs by axon count in optic nerves with severe damage [21, 37-40].

\section{Pattern electroretinography}

PERG was performed as previously described [41]. Briefly, mice were anaesthetized using ketamine/xylazine [35] and their body temperature was maintained at 37 ${ }^{\circ} \mathrm{C}$. Eyes were stimulated asynchronously by contrastreversal of gratings ( 0.05 cycles/degree, $100 \%$ contrast) generated on LED tablets. PERG signals were acquired using subcutaneous needles placed in the snout. Waveforms were determined using the average of three consecutive repetitions.

\section{RNA isolation from cultured microglia}

Primary mixed cortical cultures of glial cells from 3-dayold pups were generated and microglia were fluorescently labeled and sorted as previously described [18]. In brief, 17 days after plating, cultures were dissociated (HyClone Trypsin .25\%; Thermo Scientific) and resuspended in FACS buffer: HBSS (Gibco; Invitrogen 14025) supplemented with 2\% BSA (Sigma-Aldrich, A7906) and containing $1 \mathrm{U} / \mu \mathrm{l}$ SUPERase $\operatorname{In}^{\mathrm{TM}}$ RNase Inhibitor (Ambion; Life Technologies, AM2694). Cells were centrifuged at $1305 \mathrm{~g}$ for $5 \mathrm{~min}$ and suspended in $50 \mu \mathrm{l}$ of fresh FACS buffer to wash. The cells were stained for 1 $\mathrm{h}$ at $4{ }^{\circ} \mathrm{C}$ with chicken anti-GFAP (Abcam, ab4674) to label astrocytes and rabbit anti-IBA1 (Wako, 016-20001) to label microglial cells. Cells were washed three times and incubated for $30 \mathrm{~min}$ at $4{ }^{\circ} \mathrm{C}$ with secondary antibodies: donkey anti-rabbit 647 (Invitrogen, A31573) and goat anti-chicken 488 (Invitrogen, A11039). Samples were re-suspended in $200 \mu \mathrm{l}$ of FACS buffer and sorted on BD Biosciences LSR II SORP. Purified microglia were collected separately and stored in RLT Buffer (QIAGEN, 79216) at $-80{ }^{\circ} \mathrm{C}$. Total RNA was isolated (QIAGEN, 74104) from purified samples from D2.C3ar1 ${ }^{-/-}$and D2.C3arl ${ }^{+/+}$mice.

\section{RNA-sequencing and analysis of differentially expressed} genes

The steps taken to produce sequencing libraries have been previously reported [18]. In brief, starting with 5 ng of high-quality RNA, sequencing libraries were constructed using Ovation RNA-Seq V2 and TruSeq DNA sample prep kit v2 kits. Libraries were sequenced on a HiSeq 2000 sequencer from Illumina. Reads with $70 \%$ of their bases having a base quality score $\geq 30$ were retained for further analysis. Read alignment and expression estimation were performed using TopHat v 2.0.7 [42] and HTSeq [43] with default parameters against mouse genome (build-mm10). Differentially expressed (DE) genes between groups were identified using edgeR (v 3.8.5) [44] following the removal of lowly expressed genes (counts per million $<1$ in more than two samples). The DE gene set was analyzed using ingenuity pathway analysis (IPA) software. Results for enrichment of IPA canonical pathways and upstream regulator terms are shown.

\section{Myeloid-derived cell counting by flow cytometry}

Mice were euthanized and eyes were immediately enucleated. Retinas, optic nerves, and spleens were dissected in ice-cold, filter sterilized HBSS (Gibco; 14175-095) and placed in HBSS with dispase $(5 \mathrm{U} / \mathrm{ml}$ ) (Stemcell Technologies), DNase I (2000 U/ml) (Worthington Biochemical), and SUPERase (1 U/ $\mu \mathrm{l})$ (ThermoFisher Scientific). The tissues were shaken at $350 \mathrm{rpm}$ for $60 \mathrm{~min}$ at $37{ }^{\circ} \mathrm{C}$ in an Eppendorf Thermomixer $\mathrm{R}$ and then titrated with a $200 \mu \mathrm{l}$ pipette to dissociate cells. Cells were centrifuged at $3000 \mathrm{~g}$ for $5 \mathrm{~min}$ and suspended in a new solution by titration. Ovomucoid trypsin inhibitors $(10 \mathrm{mg} / \mathrm{ml})$ were added to the $2 \%$ BSA in HBSS block solution to inhibit proteases. Samples were kept on ice and protected from light for blocking and antibody incubations. Primary antibody solution contained anti-Cd11b, anti-CD45, antiCd11c, and DAPI. Samples were blocked for $1 \mathrm{~h}$, incubated with primary antibodies in block solution for $2 \mathrm{~h}$, washed $3 \times$, incubated in secondary antibodies for $1 \mathrm{~h}$, washed $3 \times$, and then suspended in block solution for flow cytometry on BD Biosciences LSR II SORP. Tissue collected from the spleen and processed the same was used to guide analysis of the myeloid cell populations.

\section{Statistics}

Comparisons of mean IOP levels, RGC layer neuron counts, PERG amplitudes, and myeloid cell population numbers were comparisons between $\mathrm{C}_{3} \mathrm{arl}^{-/-}$and $\mathrm{C} 3 \mathrm{ar}^{+/+}$ mice at each age shown and performed using Student's $t$ tests. Each assay involved multiple comparisons and $P<$ 0.01 was considered significant. Fisher's exact test of independence was used to compare the number of nerves at each grade level at a specific age between $\mathrm{C}_{3} \mathrm{arl}^{-1-}$ and $\mathrm{C} \mathrm{ar}^{+/+}$mice. $P<0.01$ was considered significant. DE genes 
from RNA sequencing experiments were adjusted for multiple testing using FDR. Genes were considered to be differentially expressed between $\mathrm{C}_{3} \mathrm{arl}^{-/-}$and $\mathrm{C}_{3} \mathrm{arl}^{+/+}$at FDR $<0.01$. Ingenuity pathway analysis software was used to assess enrichment of terms (canonical pathways and upstream regulators) by $\mathrm{DE}$ genes. Benjamin-Hochberg adjusted $P$ values $<0.05$ were considered significant. The complete list of genes detected by RNA sequencing was used as the background gene list. Expression data and analyses are provided in Tables S1, S2, and S3.

\section{Results}

\section{C3ar1-deficient DBA/2J mice developed elevated} intraocular pressure similar to C3ar1 sufficient mice

DBA/2J mice inherit a depigmenting iris disease that leads to high IOP and glaucoma [33, 39]. Immune cells that are likely to express C3ar1 contribute to iris damage and the development of ocular hypertension $[45,46]$. To determine whether C3ar1 deficiency affected iris disease or IOP elevation, eyes of $\mathrm{C}_{3 \mathrm{arl}^{-/-}}$mice and their $\mathrm{C}_{\mathrm{arr}}{ }^{+/+}$littermates were examined regularly beginning at 6 months of age. No differences between genotypes were observed in the onset and progression of the iris disease (Fig. 1a) or IOP elevation (Fig. 1b). In C3ar1-deficient mice, high IOP sufficient to cause ocular hypertensive damage was observed, similar to standard DBA/2J mice [39].

\section{C3ar1 deficiency lowered the incidence of glaucomatous} degeneration in D2 mice at $\mathbf{1 0 . 5}$ months of age

The presence of optic nerve degeneration in an eye can be explicitly determined by identifying degenerating axons and scarred regions with axon loss in the optic nerve (Fig. 2a) [21, 37-40]. The percentage of eyes with optic nerve degeneration in $\mathrm{C}_{3} \mathrm{arl}^{-/-}$and $\mathrm{C}^{-\mathrm{arl}^{+/+}}$mice was compared at 10.5 and 12.5 months of age. At 10.5 months of age, significantly fewer eyes from $\mathrm{C}_{3 \mathrm{arl}}{ }^{-/-}$mice had degeneration (Fig. 2b), suggesting that C3arl deficiency decreased the risk of ocular hypertensive injury. By 12.5 months of age, C3ar1-deficient mice were no longer protected from glaucomatous degeneration (Fig. 2b). Thus, C3ar1 was not the sole trigger for degeneration, but did promote optic nerve damage.

Eyes from $\mathrm{C}_{3} \mathrm{arl}^{-1-}$ mice with healthy optic nerves had a normal number of RGC layer neurons, suggesting that C3ar1 deficiency had not caused abnormal loss of RGCs or amacrine cells (Fig. 2c, d). In eyes with optic nerve degeneration, the loss of RGC layer neurons was independent of C3ar1 genotype (Fig. 2c, d). The observed loss of approximately half of RGC layer neurons is consistent with cell loss due to optic nerve injury, where the majority of RGCs die and amacrine cells are not affected [37, 40]. These data indicate that $\mathrm{C} \mathrm{arl}^{-1-}$ mice had the same type of injury as standard D2 mice.

To investigate changes in $\mathrm{RGC}$ function in $\mathrm{C}_{3} \mathrm{arl}^{-/-}$ mice, pattern electroretinography was used. PERG amplitude is a sensitive measure of RGC activity and detects RGC dysfunction in ocular hypertensive DBA/2J mice [47, 48]. PERG amplitude was recorded at 4 months of age, prior to the elevation of IOP, and 10 months of age, when lower amplitudes are expected due to ocular hypertension and not due to the degeneration that typically occurs at slightly older ages. C3arl deficiency had no effect on the average PERG amplitude in young mice. $\mathrm{C}_{3} \mathrm{arl}^{-/-}$mice also

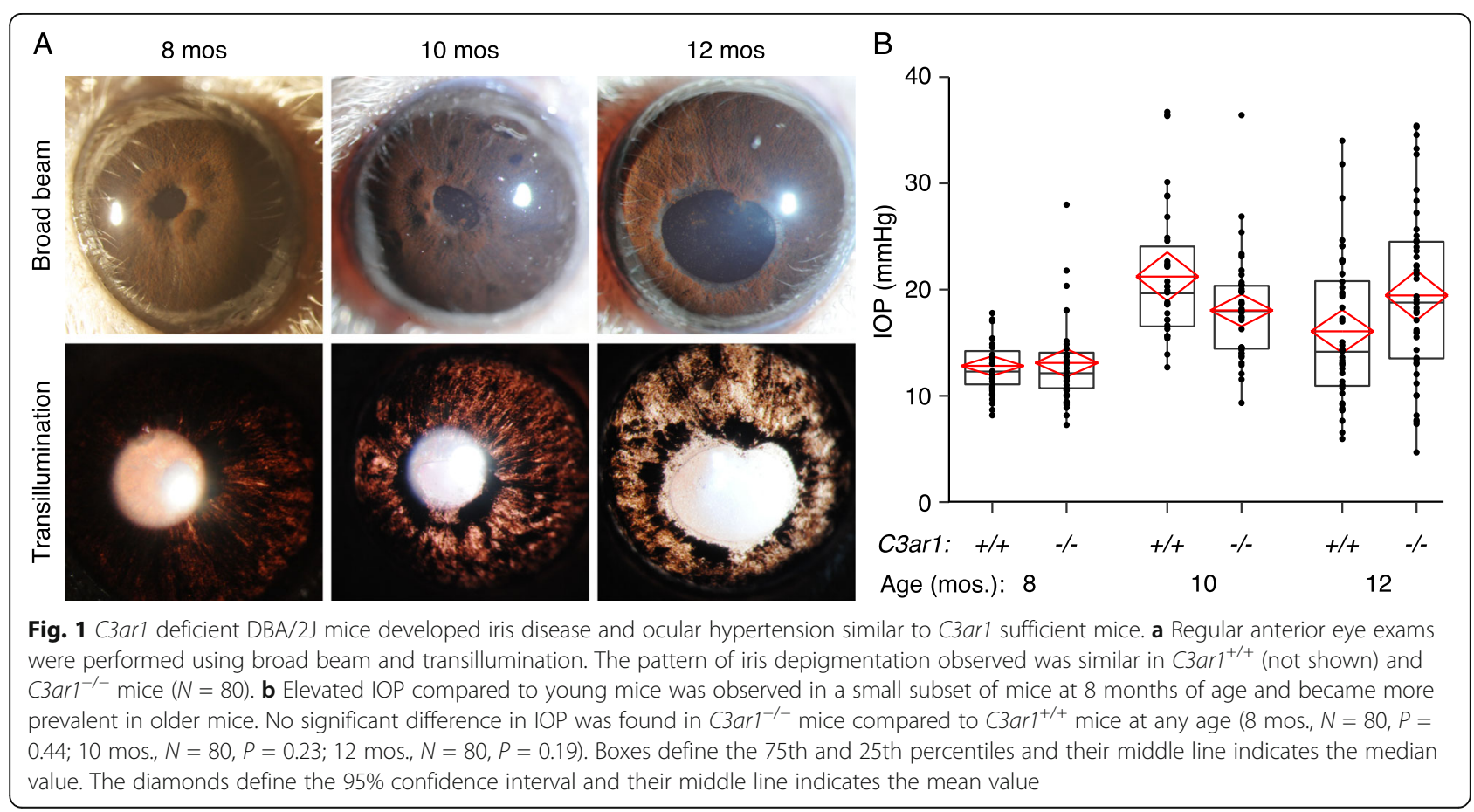




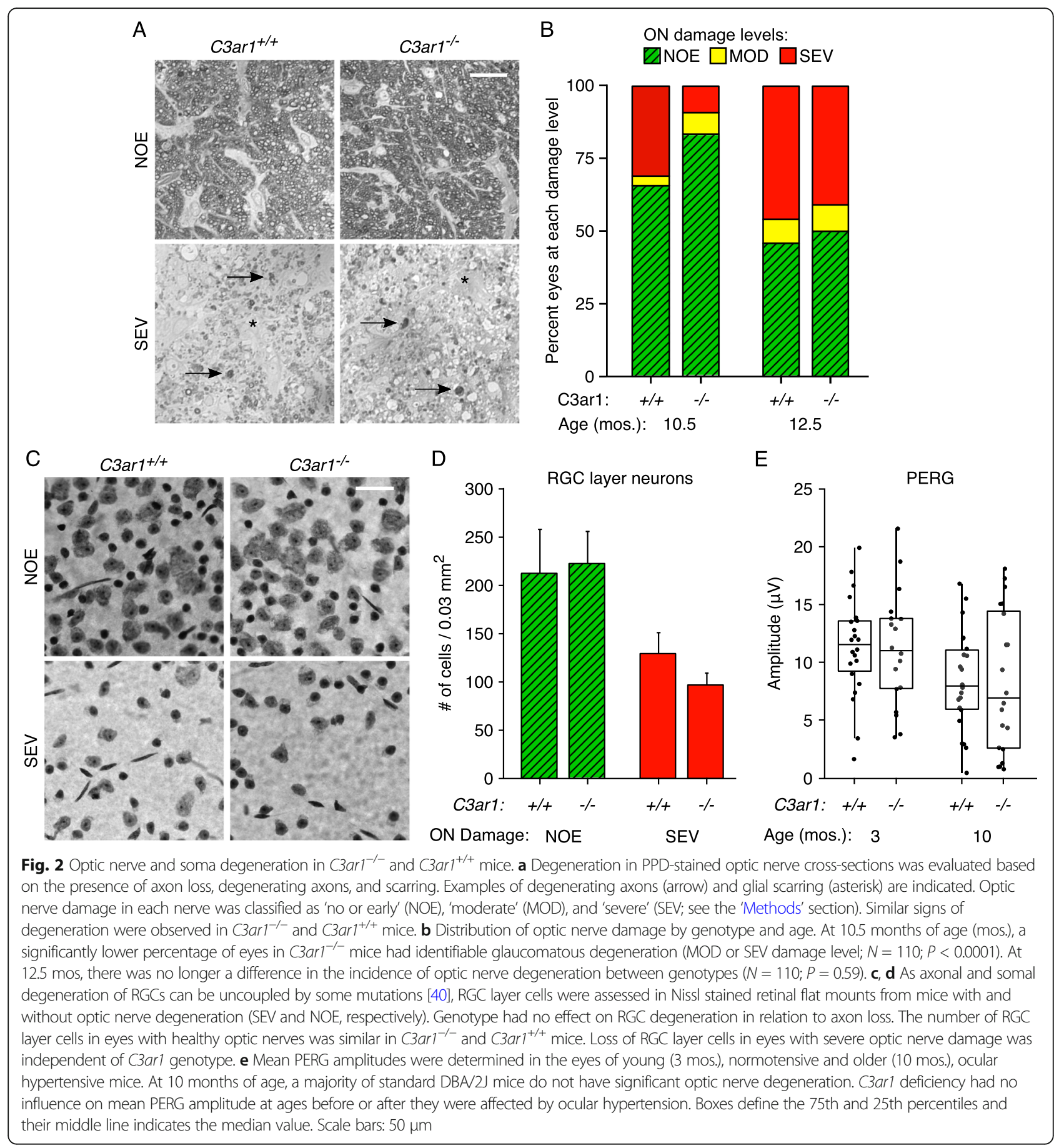

had a similar decrease in PERG amplitude due to chronically elevated IOP as $\mathrm{C} \mathrm{arl}{ }^{+/+}$mice. Thus, C3arl deficiency did not prevent changes in RGC activity associated with ocular hypertension (Fig. 2c).

\section{Ocular hypertension affects C3ar1 expression in the optic nerve head}

In DBA/2J mice, observable injury occurs at the optic nerve head $(\mathrm{ONH})$ prior to other regions of the optic nerve [37]. At this same time point, the expression of C3ar1 increased in the ONH (2.0- to 3.4-fold; $q<0.05)$, but not in the retina (1.0-fold; $q=0.85$ ) based on publicly available data [49]. In the healthy brain, it is well established that microglia primarily express C3ar1, with low or no expression in other cells (Fig. 3a, b, [50-52]). In addition, higher levels of expression have been observed in subsets of microglia thought to mediate neuroinflammation, such as disease-associated microglia in 


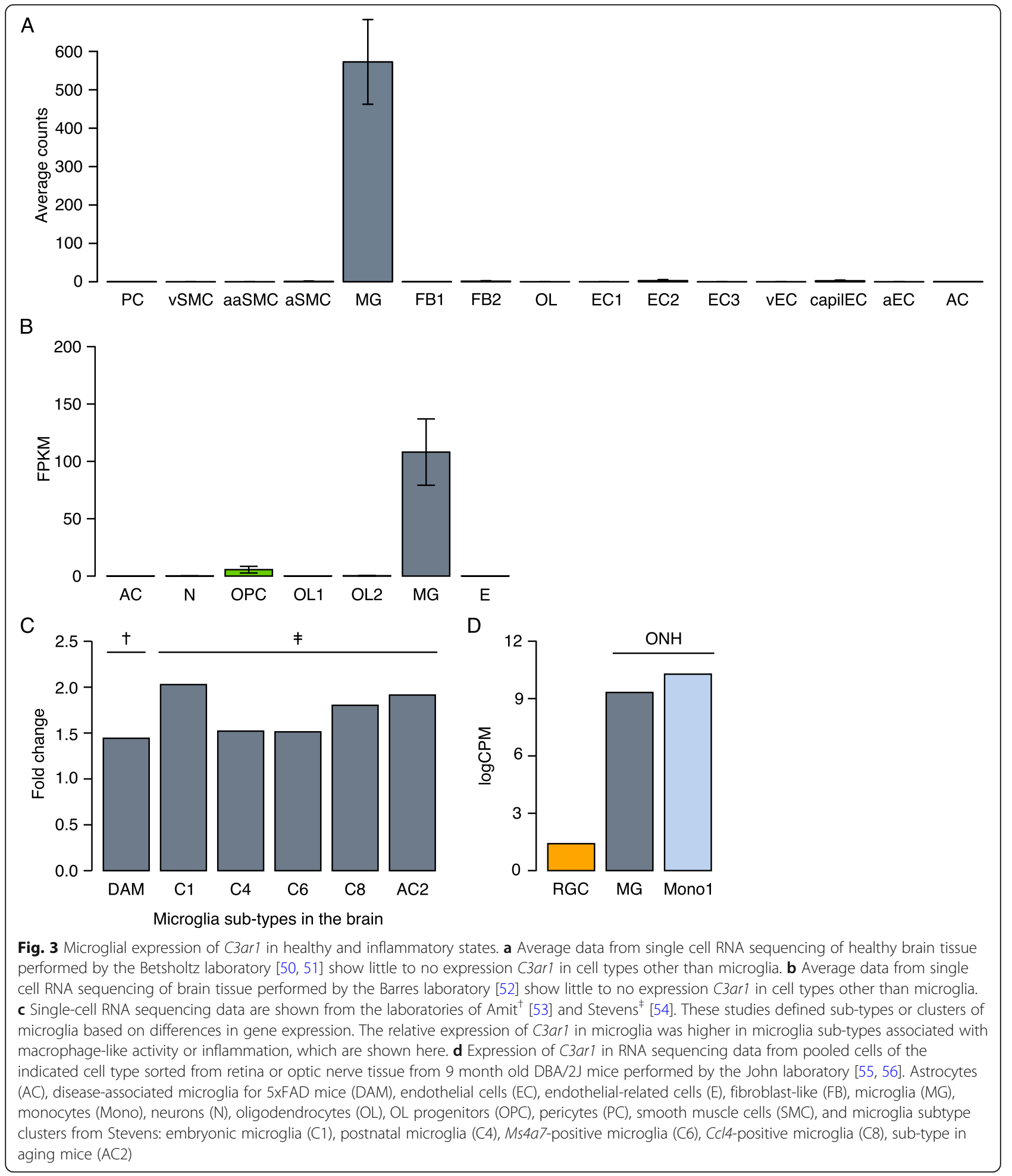

5xFAD mice, a widely used mouse model of Alzheimer's disease and Ccl3/Ccl4-positive microglia in aged and white matter-injured brain, as well as at embryonic and postnatal ages of development (Fig. 3c, [53, 54]). This expression pattern is consistent with cell-type specific data from DBA/2J mice. ONH microglia and infiltrating monocytes express C3ar1 at high levels, while RGCs express C3ar1 at a lower level (Fig. 3d, [55, 56]). Thus, 
C3ar1 deficiency in microglia and monocytes may affect their function or number in the $\mathrm{ONH}$ of ocular hypertensive eyes based on these expression data.

\section{C3ar1 deficiency altered the inflammatory phenotype of cultured microglia}

To determine how C3ar1 deficiency may alter microglia function, RNA sequencing was performed on microglia sorted from primary co-cultures of postnatally derived astrocytes and microglia. In culture, where gene expression is more uniform compared to DBA/2J mice, glial cells express many neuroinflammatory genes expressed in the optic nerve head of DBA/2J mice, including C3 [18]. Microglia were identified by fluorescence-activated cell sorting as IBA1-positive and GFAP-negative cells (Fig. 4a). The selected cells expressed high levels of genes associated with microglia and low levels of genes associated with astrocytes (Fig. 4b). Four hundred and eight genes were differentially expressed (DE) in microglia due to C3ar1 deficiency (Fig. 4c; $N=6$, FDR < $0.005)$.
The biological pathways most significantly enriched in DE genes included 'role of pattern recognition receptors in recognition of bacteria and viruses,' 'phagosome formation,' and 'TREM1 signaling' (Fig. 5a). A network of the top 20 enriched pathways, with connections based on having more than five genes in common, suggested that most pathways were closely interrelated and relevant to neuroinflammation and immune cell recruitment (Fig. 5b). Thus, the pathways altered by C3ar 1 deficiency regulate homeostatic and pathological responses in microglia and other immune cells. Upstream regulators of DE genes were analyzed to determine how C3ar1 deficiency may have this effect (Fig. 5c). The most significantly enriched upstream regulators were 'TCL1A,' 'IL10,' and 'LDLR.' The endogenous regulator that had the highest interconnectivity was the anti-inflammatory cytokine IL10 (Fig. 5d). In addition, the predicted regulator associated with the most DE genes was dexamethasone, a corticosteroid that prevents inflammation. These data show that C3arl deficiency significantly altered the expression of inflammatory genes and signaling pathways in microglia.

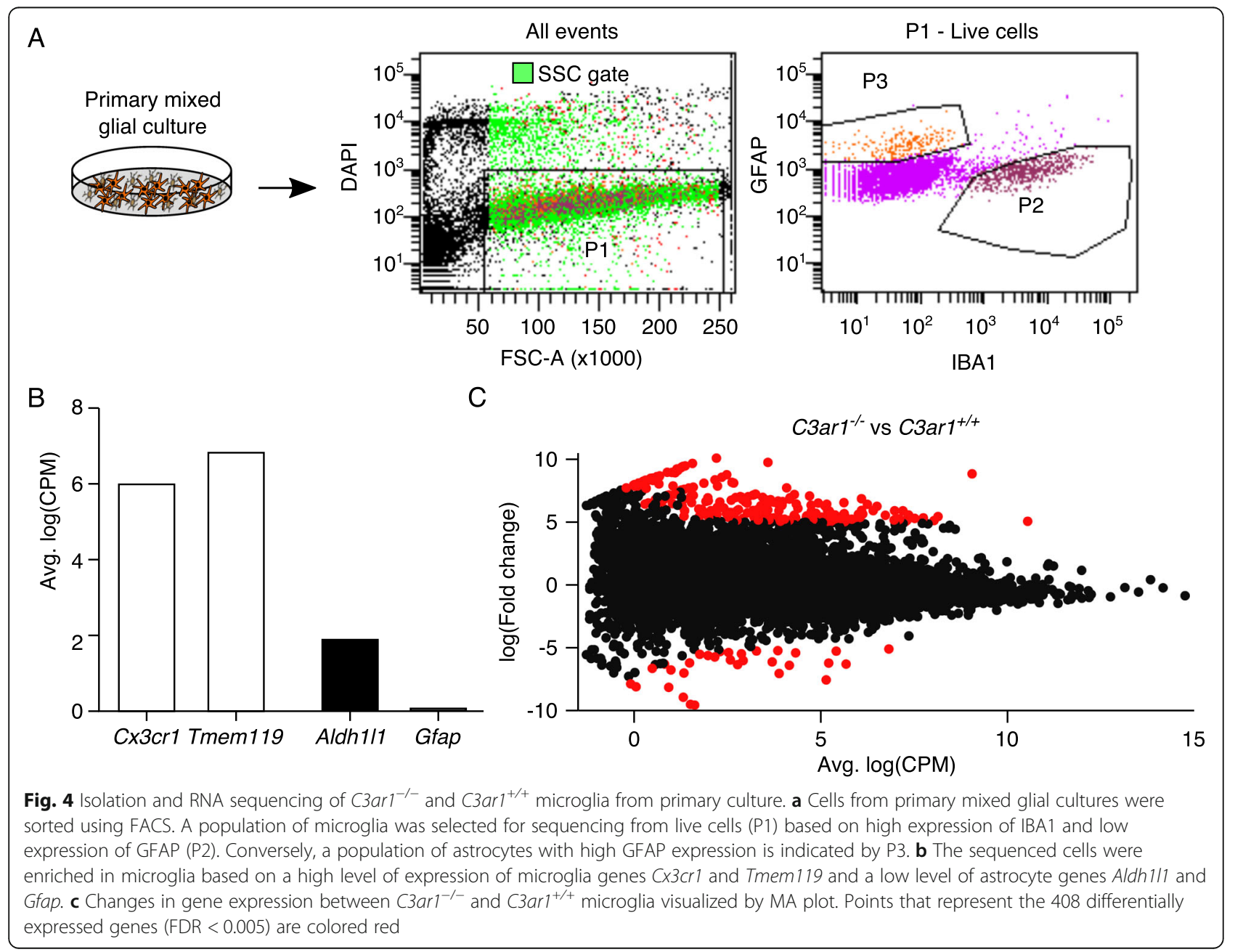




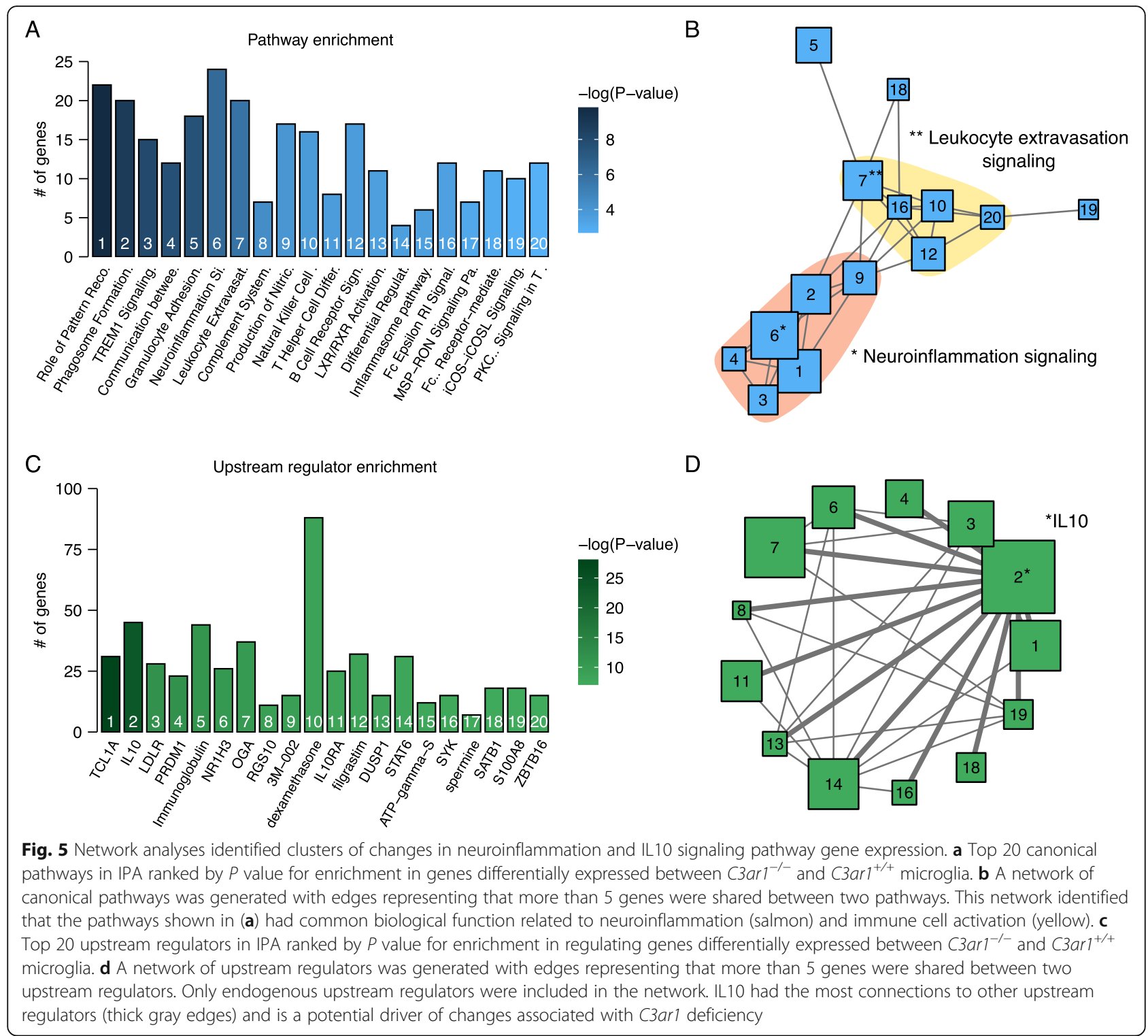

\section{C3ar1 deficiency altered myeloid cell populations in the optic nerve head}

In C3ar1-deficient DBA/2J mice, changes in inflammatory gene expression are likely to change the localization or reactivity of microglia and monocytes. To investigate this in DBA/2J mice, the population of myeloid-derived cells in the retina and the optic nerve head was assessed by flow cytometry at 10 months of age (Fig. 6a). In the retina, no difference was observed between $\mathrm{C}_{3 \mathrm{arl}}{ }^{+/+}$and $C 3 \mathrm{arl}^{-/-}$mice in the percentage of myeloid-derived cells, including CD45 $5^{\mathrm{hi}}$ and $\mathrm{Cd} 11 \mathrm{c}^{+}$monocytes (Fig. 6b). Thus, C3ar1 deficiency did not have a general effect on the number of these cells in neural tissue exposed to ocular hypertension. In contrast to the retina, the $\mathrm{ONH}$ is a very small region of tissue more sensitive to ocular hypertensive stress and a location where myeloid cells likely have beneficial and harmful effects at different stages of disease $[21,55,57]$. In the $\mathrm{ONH}$ of $\mathrm{C}_{3} \mathrm{arr}^{-/-}$ mice, the number of myeloid cells was more variable compared to in $\mathrm{C}_{3} \mathrm{arl}^{+/+}$mice (Fig. 6c). These data suggest a role for C3ar1 in regulating myeloid cells in $\mathrm{ONH}$ under chronic ocular hypertensive stress.

\section{Discussion}

Interventions that target complement activation are being evaluated in many types of neurological injury and disease (reviewed in [58]). DBA/2J mice are a useful model for testing whether neurodegeneration caused by chronic ocular hypertension is prevented by targeting specific components of the complement cascade. DBA/ 2J mice have an inborn deficiency in $\mathrm{C} 5$ that prevents secretion of $\mathrm{C} 5$ and formation of both $\mathrm{C} 5 \mathrm{a}$ and the 

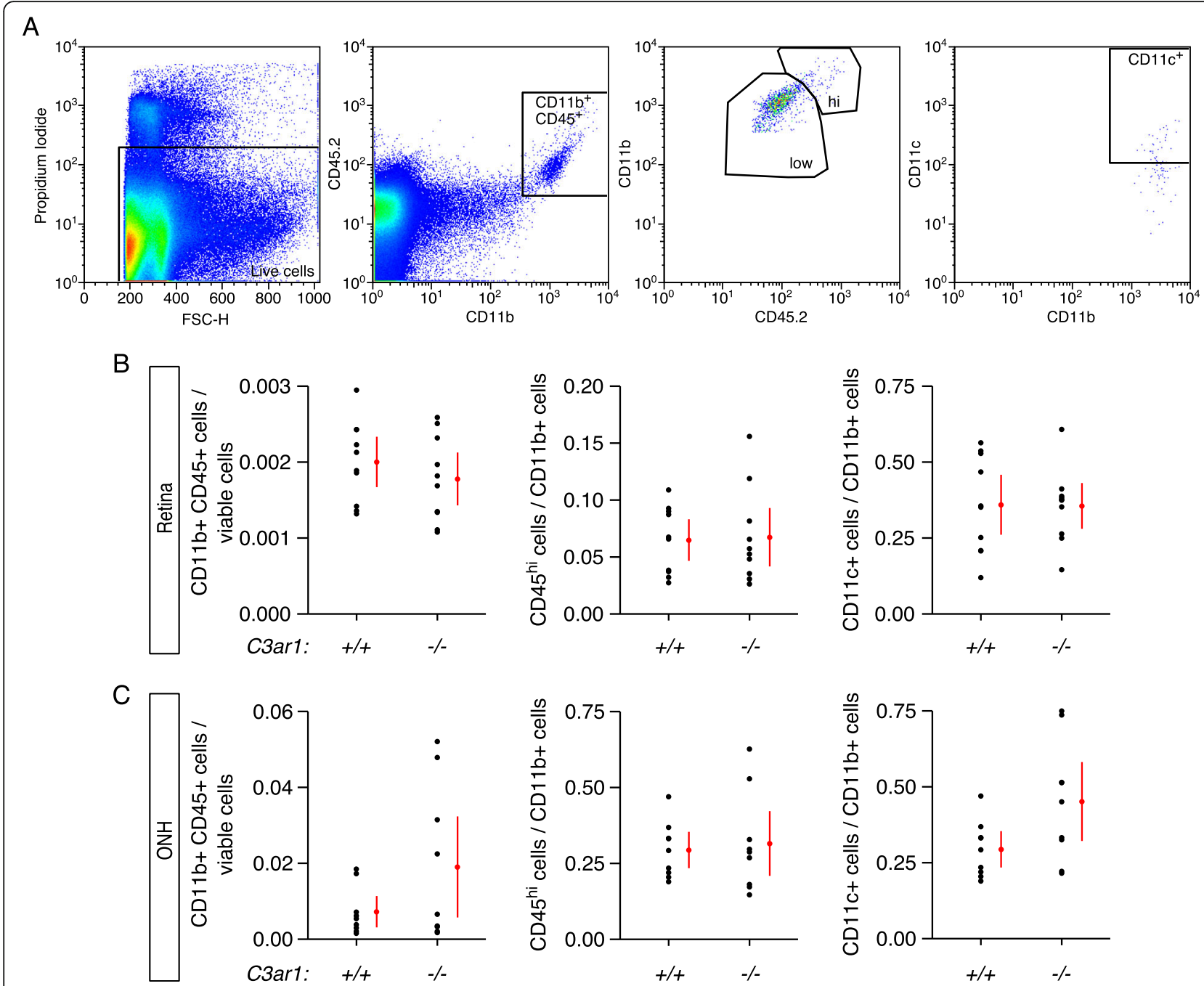

Fig. 6 C3arl deficiency altered the population of myeloid-derived cells in the ONH in a subset of eyes. a Diagram of the gating strategy used in flow cytometry to identify sub-populations of myeloid-derived cells isolated from retina and optic nerve head tissue. $\mathbf{b}$ No gross difference in the

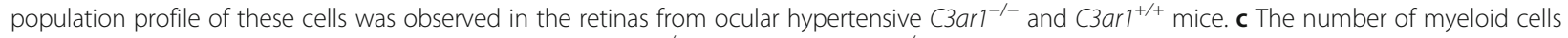
detected in optic nerve head tissue was more variable ${\mathrm{C} 3 a r 1^{-/-}}$mice than in $\mathrm{C} 3 \mathrm{ar} 1^{+/+}$mice

MAC (which requires C5b). Therefore, optic nerve damage in these mice is independent of secreted C5, which has been shown to be detrimental if present [22]. However, optic nerve damage in DBA/2J mice is still dependent on $\mathrm{C} 1 \mathrm{q}$ based on the protection against ocular hypertension observed in C1qa ${ }^{-/-}$mice [38]. To determine how $\mathrm{C} 1 \mathrm{q}$ causes permanent damage and vision loss, there are a limited number of targets remaining to investigate, such as $\mathrm{C} 3, \mathrm{C} 4$, and receptors for $\mathrm{C} 1 \mathrm{q}$. As shown here, C3a contributes to degeneration caused by ocular hypertension based on the decreased incidence of optic nerve damage at 10.5 months of age in $\mathrm{C}_{3} \mathrm{arl}^{-/-}$ mice.

Understanding why C3ar1 deficiency did not provide long-lasting protection requires understanding other damaging consequences of complement activation. Greater protection in DBA/2J mice has been achieved by disrupting C1qa [38] compared to C3arl, suggesting that C1qa triggers multiple damaging responses. A therapy targeting sites opsonized by $\mathrm{C} 3 \mathrm{~b}$ and $\mathrm{C} 4 \mathrm{~b}$, achieved by expression of CR2-Crry in retinal ganglion cells, has produced results more similar to C1qa deficiency [15]. Crry would be predicted to inhibit C3 convertase activity of the classical pathway (through $\mathrm{C} 4 \mathrm{~b}$ ) and alternative pathway (through C3b) [59], severely limiting accumulation of both C3a and $\mathrm{C} 3 \mathrm{~b}$ in the treated DBA/2J mice. The results of treatment with CR2-Crry suggest that inhibition of C3a and C3b may protect in an additive manner. In fact, DBA/2J mice that lack the C3b receptor CR3, by disruption of Itgam, are less vulnerable to optic nerve degeneration [55]. Similar to ${\mathrm{C} 3 \mathrm{arl}^{-1-}}^{-1}$ mice, $\mathrm{Itgam}^{-1-}$ mice are not protected as well as $\mathrm{Clqa}^{-/-}$and CR2-Crry treated mice. These results 
suggest that complement activated peptides and opsonization products may independently contribute to optic nerve degeneration. Thus, targeting both types of receptors, such as by disrupting both C3arl and Itgam expression, may protect to a greater degree than targeting C3ar1 or Itgam alone and explain the full effect of treatment with CR2-Crry or disrupting C1q.

Complement activation is primarily expected to guide a targeted immune cell response in DBA/2J mice, given the deficiency of secreted C5 and lack of MAC activation. A type of targeted response to $\mathrm{C} 1 \mathrm{q}$ and $\mathrm{C} 3 \mathrm{a}$ by microglia and other myeloid cells is to phagocytose neuronal blebs or dying neurons and limiting proinflammatory cytokine production [60-62]. C1q regulates dendritic and synaptic pruning during development and ocular hypertension in the retina [23, 63]. C3ar1 has been implicated in mediating synaptic plasticity [26] and phagocytosis by microglia [64] in cell culture and a mouse model relevant to Alzheimer's disease, but has not yet been in models of glaucoma. In this study, C3ar1 deficiency did not influence PERG readings that occur in conjunction with synapse loss and dendritic remodeling. It is possible that C3AR1 signaling does not strongly affect phagocytosis or synapse loss in an ocular hypertensive setting and that C3AR1 signaling has detrimental effects in glaucoma through a different mechanism.

To predict how C3arl deficiency might affect microglial cell biology, cell culture of microglia was used as a model to identify differences in gene expression caused by C3ar1 deficiency. Numerous genes associated with inflammation were affected by $C 3$ ar 1 expression raising the possibility that the effect of disrupting C3arl on neurodegeneration may be caused by a change in inflammation. More specifically, a significant number of changes in gene expression were associated with downstream effects of IL10 signaling. These data predict crosstalk between C3AR1 and IL10 in microglia. An interaction between C3AR1 and IL10 has been shown previously in another type of immune cell; C3AR1 inhibited IL10 production by $\mathrm{CD}^{+}$tumor-infiltrating lymphocytes [65]. Interestingly, microglia can produce IL10 and autocrine signaling by IL10 has been suggested to regulate microglial activation [66]. However, it has not been determined whether C3AR1 has an effect on IL10 production or the expression of related genes and proteins in microglia in an ocular hypertensive setting. Furthermore, little is known about whether IL10 signaling is activated or has a function in glaucomatous neurodegeneration. Addressing these questions will help resolve whether C3ar1 deficiency altered disease risk by modulating inflammation or through a different mechanism.

C3a may also recruit monocytes that express C3ar1. A subclass of monocytes (CD11b-positive, CD45-hi, and Cd11c-positive) that express C3ar1 increase in number in tissue affected by ocular hypertension [21], but how they are recruited is not known. C3a may influence their recruitment based on flow cytometry data presented here, although this is unresolved. In some eyes from ${\mathrm{C} 3 a r 1^{-1-}}^{-1}$ mice, the number of myeloid cells in the optic nerve head appeared to be increased as observed by flow cytometry. It is possible that myeloid cells have a protective role early in disease and that this increase helped prevent optic nerve damage. In this study, it was not feasible to address these possibilities in more depth due to the spontaneous nature of IOP elevation, variability between eyes, and the unexpected increase in myeloid cell population variability in the $\mathrm{ONH}$ of $\mathrm{C}_{3 \mathrm{arl}^{-1-}}$ mice. A larger study using DBA/2J mice or another model with chronic ocular hypertension could address how C3ar1 alters microglia and monocyte localization and function in this type of glaucoma. All of the hypotheses are consistent with the idea that targeting myeloid cells with therapy may improve disease outcomes in glaucoma.

In DBA/2J mice, ONH astrocytes express C3 [18], a marker associated with a neurotoxic phenotype in some conditions [67]. However, C3 deficiency was shown to increase vulnerability of the optic nerve to ocular hypertensive damage [18]. This is counterintuitive to harmful effects of C3a and C3b and was suggested to implicate early protective responses by astrocytes in glaucoma. The role of $\mathrm{C} 3$ in neuroprotective and neurotoxic functions of astrocytes needs to be determined. Astrocytes in DBA/2J mice may be capable of both neuroprotective and neurotoxic function that depends on the activation of specific extracellular receptors. In this case, C3ar1 deficiency may protect by decreasing the extracellular signals produced by microglia and infiltrating monocytes, including C1Q, IL1A, and TNF [67], that trigger a neurotoxic response. Testing the function of $\mathrm{Clq}$ receptors and $\mathrm{C} 3$ in astrocytes in DBA/2J mice could better define the effects of complement activation and show whether astrocytes directly contribute to optic nerve degeneration.

\section{Conclusion}

Signaling through C3AR1 promoted neurodegenerative processes in a model of glaucoma with chronic ocular hypertension and neuroinflammation. C3ar1 deficiency caused changes to IL10-related signaling pathways in cultured microglia, pathways predicted to have an important effect on microglia reactivity. In this regard, genetic and other factors that influence expression of C3ar1, C3, or other members of the complement cascade may predispose people to beneficial or harmful neuroinflammatory responses by affecting microglial or astrocytic reactivity. Targeting myeloid cells and complement-mediated inflammation pathways with therapies will likely be a 
beneficial addition to neuroprotective therapeutic strategies by reducing the impact of harmful inflammatory processes.

\section{Supplementary Information}

The online version contains supplementary material available at https:/doi. org/10.1186/s12974-020-02011-z.

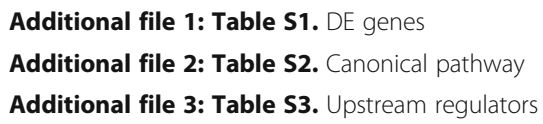

\section{Abbreviations}

C1q: Complement component 1q complex; C3ar1: C3a receptor; DE: Differentially expressed; IOP: Intraocular pressure; IPA: Ingenuity Pathway Analysis software; NOE: No or early, no readily detectible axon loss; ONH: Optic nerve head; MAC: Membrane attack complex; MOD: Moderate, less than $50 \%$ of axons damaged/lost; PERG: Pattern electroretinography; PPD: Paraphenylenediamine; SEV: Severe, more than $50 \%$ of axons damaged/ lost

\section{Acknowledgements}

The authors wish to thank Mimi DeVries, Amy Bell, and Pete Finger for contributions to this work.

\section{Authors' contributions}

SJ and GH conceived the study. JH, PW, CB, NF, and JT performed experiments. $\mathrm{JH}$ and $\mathrm{HY}$ performed computational analyses. JH, PW, SJ, and $\mathrm{GH}$ analyzed the data. JH wrote the manuscript that was edited by PW, SJ, and $\mathrm{GH}$. All authors approved the final version.

\section{Funding}

This work was funded in part by EY011721 (SWMJ), EY021525 (GRH), Vetenskapsrådet 2018-02124 (PAW), the Barbara and Joseph Cohen Foundation, and the Partridge Foundation. Partial support was provided to SWMJ by P30EY019007 and Research to Prevent Blindness. PAW is supported by Karolinska Institutet in the form of a Board of Research Faculty Funded Career Position and by St. Erik Eye Hospital philanthropic donations. GRH is the Diana Davis Spencer Foundation Chair for Glaucoma Research. SWMJ is an Investigator of $\mathrm{HHMI}$.

\section{Availability of data and materials}

The datasets during and/or analyzed during the current study available from the corresponding author on reasonable request.

\section{Ethics approval and consent to participate}

All animals were treated according to the guidelines of the Association for Research in Vision and Ophthalmology for use of animals in research. The Animal Care and Use Committee of The Jackson Laboratory approved all experimental procedures.

\section{Consent for publication}

Not applicable.

\section{Competing interests}

The authors declare that they have no competing interests.

\section{Author details}

${ }^{1}$ The Jackson Laboratory, Bar Harbor, ME, USA. ${ }^{2}$ Division of Eye and Vision, Department of Clinical Neuroscience, St. Erik Eye Hospital, Karolinska Institutet, Stockholm, Sweden. ${ }^{3}$ Zuckerman Mind Brain Behavior Institute, New York, NY, USA. ${ }^{4}$ Department of Ophthalmology, Tufts University of Medicine, Boston, MA, USA. ${ }^{5}$ Howard Hughes Medical Institute, Department of Ophthalmology, Columbia University Medical Center, and Zuckerman Mind Brain Behavior Institute, New York, NY, USA. '5ackler School of Graduate Biomedical Sciences, Tufts University School of Medicine, Boston, MA, USA. ${ }^{7}$ Graduate School of Biomedical Sciences and Engineering, University of Maine, Orono, ME, USA.
Received: 30 June 2020 Accepted: 28 October 2020

Published online: 11 November 2020

\section{References}

1. Tham YC, Li X, Wong TY, Quigley HA, Aung T, Cheng CY. Global prevalence of glaucoma and projections of glaucoma burden through 2040: a systematic review and meta-analysis. Ophthalmology. 2014;121(11):2081-90.

2. Soto I, Howell GR. The complex role of neuroinflammation in glaucoma. Cold Spring Harb Perspect Med. 2014;4(8):a017269.

3. Tezel G, Wax MB. The immune system and glaucoma. Curr Opin Ophthalmol. 2004;15(2):80-4.

4. Kuehn MH, Kim CY, Ostojic J, Bellin M, Alward WL, Stone EM, et al. Retinal synthesis and deposition of complement components induced by ocular hypertension. Exp Eye Res. 2006;83(3):620-8.

5. Stasi $K$, Nagel D, Yang X, Wang RF, Ren L, Podos SM, et al. Complement component $1 \mathrm{Q}(\mathrm{C} 1 \mathrm{Q})$ upregulation in retina of murine, primate, and human glaucomatous eyes. Invest Ophthalmol Vis Sci. 2006;47(3):1024-9.

6. Tezel G, Yang X, Luo C, Kain AD, Powell DW, Kuehn MH, et al. Oxidative stress and the regulation of complement activation in human glaucoma. Invest Ophthalmol Vis Sci. 2010:51(10):5071-82.

7. Morgan BP. The membrane attack complex as an inflammatory trigger. Immunobiology. 2016;221(6):747-51.

8. Peng Q, Li K, Sacks SH, Zhou W. The role of anaphylatoxins C3a and C5a in regulating innate and adaptive immune responses. Inflamm Allergy Drug Targets. 2009;8(3):236-46

9. Coulthard LG, Woodruff TM. Is the complement activation product C3a a proinflammatory molecule? Re-evaluating the evidence and the myth. J Immunol. 2015;194(8):3542-8.

10. Triantafilou K, Hughes TR, Triantafilou M, Morgan BP. The complement membrane attack complex triggers intracellular $\mathrm{Ca} 2+$ fluxes leading to NLRP3 inflammasome activation. J Cell Sci. 2013:126(Pt 13):2903-13.

11. Laudisi F, Spreafico R, Evrard M, Hughes TR, Mandriani B, Kandasamy M, et al. Cutting edge: the NLRP3 inflammasome links complement-mediated inflammation and IL-1 beta release. J Immunol. 2013;191(3):1006-10.

12. Hawksworth OA, Li XX, Coulthard LG, Wolvetang EJ, Woodruff TM. New concepts on the therapeutic control of complement anaphylatoxin receptors. Mol Immunol. 2017:89:36-43.

13. Xie CB, Jane-Wit D, Pober JS. Complement membrane attack complex: new roles, mechanisms of action, and therapeutic targets. Am J Pathol. 2020;190(6):1138-50.

14. Miyahara T, Kikuchi T, Akimoto M, Kurokawa T, Shibuki H, Yoshimura N. Gene microarray analysis of experimental glaucomatous retina from cynomologous monkey. Invest Ophthalmol Vis Sci. 2003;44(10):4347-56.

15. Bosco A, Anderson SR, Breen KT, Romero CO, Steele MR, Chiodo VA, et al. Complement C3-targeted gene therapy restricts onset and progression of neurodegeneration in chronic mouse glaucoma. Mol Ther. 2018;26(10):2379-96.

16. Jha P, Banda H, Tytarenko R, Bora PS, Bora NS. Complement mediated apoptosis leads to the loss of retinal ganglion cells in animal model of glaucoma. Mol Immunol. 2011:48(15-16):2151-8

17. Reinehr S, Reinhard J, Gandej M, Gottschalk I, Stute G, Faissner A, et al. S100B immunization triggers NFkappaB and complement activation in an autoimmune glaucoma model. Sci Rep. 2018;8(1):9821.

18. Harder JM, Braine CE, Williams PA, Zhu X, MacNicoll KH, Sousa GL, et al. Early immune responses are independent of RGC dysfunction in glaucoma with complement component C3 being protective. Proc Natl Acad Sci U S A. 2017:114(19):E3839-E48.

19. Kuehn MH, Kim CY, Jiang B, Dumitrescu AV, Kwon YH. Disruption of the complement cascade delays retinal ganglion cell death following retinal ischemia-reperfusion. Exp Eye Res. 2008;87(2):89-95.

20. Silverman SM, Kim BJ, Howell GR, Miller J, John SW, Wordinger RJ, et al. C1 propagates microglial activation and neurodegeneration in the visual axis following retinal ischemia/reperfusion injury. Mol Neurodegener. 2016;11:24.

21. Howell GR, Macalinao DG, Sousa GL, Walden M, Soto I, Kneeland SC, et al. Molecular clustering identifies complement and endothelin induction as early events in a mouse model of glaucoma. J Clin Invest. 2011;121(4):1429-44.

22. Howell GR, Soto I, Ryan M, Graham LC, Smith RS, John SW. Deficiency of complement component 5 ameliorates glaucoma in DBA/2J mice. J Neuroinflammation. 2013;10:76

23. Williams PA, Tribble JR, Pepper KW, Cross SD, Morgan BP, Morgan JE, et al. Inhibition of the classical pathway of the complement cascade prevents early dendritic and synaptic degeneration in glaucoma. Mol Neurodegener. 2016;11:26. 
24. Howell GR, MacNicoll KH, Braine CE, Soto I, Macalinao DG, Sousa GL, et al. Combinatorial targeting of early pathways profoundly inhibits neurodegeneration in a mouse model of glaucoma. Neurobiol Dis. 2014;71:44-52.

25. Klos A, Tenner AJ, Johswich KO, Ager RR, Reis ES, Kohl J. The role of the anaphylatoxins in health and disease. Mol Immunol. 2009;46(14):2753-66.

26. Litvinchuk A, Wan YW, Swartzlander DB, Chen F, Cole A, Propson NE, et al. Complement C3aR inactivation attenuates tau pathology and reverses an immune network deregulated in tauopathy models and Alzheimer's disease. Neuron. 2018;100(6):1337-53 e5.

27. Lian $H$, Litvinchuk $A$, Chiang AC, Aithmitti N, Jankowsky JL, Zheng $H$. Astrocyte-microglia cross talk through complement activation modulates amyloid pathology in mouse models of Alzheimer's disease. J Neurosci. 2016;36(2):577-89.

28. Lian H, Yang L, Cole A, Sun L, Chiang AC, Fowler SW, et al. NFkappaBactivated astroglial release of complement C3 compromises neuronal morphology and function associated with Alzheimer's disease. Neuron. 2015;85(1):101-15.

29. Jarlestedt K, Rousset Cl, Stahlberg A, Sourkova H, Atkins AL, Thornton C, et al. Receptor for complement peptide C3a: a therapeutic target for neonatal hypoxic-ischemic brain injury. FASEB J. 2013;27(9):3797-804.

30. Boos L, Campbell IL, Ames R, Wetsel RA, Barnum SR. Deletion of the complement anaphylatoxin C3a receptor attenuates, whereas ectopic expression of $\mathrm{C} 3 \mathrm{a}$ in the brain exacerbates, experimental autoimmune encephalomyelitis. J Immunol. 2004;173(7):4708-14.

31. Humbles AA, Lu B, Nilsson CA, Lilly C, Israel E, Fujiwara $Y$, et al. A role for the C3a anaphylatoxin receptor in the effector phase of asthma. Nature. 2000; 406(6799):998-1001.

32. Smith RS, Zabaleta A, Kume T, Savinova OV, Kidson SH, Martin JE, et al Haploinsufficiency of the transcription factors FOXC1 and FOXC2 results in aberrant ocular development. Hum Mol Genet. 2000;9(7):1021-32.

33. John SW, Smith RS, Savinova OV, Hawes NL, Chang B, Turnbull D, et al. Essential iris atrophy, pigment dispersion, and glaucoma in DBA/2J mice. Invest Ophthalmol Vis Sci. 1998;39(6):951-62.

34. John SW, Hagaman JR, MacTaggart TE, Peng L, Smithes O. Intraocular pressure in inbred mouse strains. Invest Ophthalmol Vis Sci. 1997;38(1):249-53.

35. Savinova OV, Sugiyama F, Martin JE, Tomarev SI, Paigen BJ, Smith RS, et al. Intraocular pressure in genetically distinct mice: an update and strain survey. BMC Genet. 2001;2:12.

36. Smith RSZA, Kume T, Savinova OV, Kidson SH, et al. General and specific histopathology. In: Smith RS, editor. Systemic evaluation of the mouse eye. New York: CRC Press; 2002. p. 265-97.

37. Howell GR, Libby RT, Jakobs TC, Smith RS, Phalan FC, Barter JW, et al. Axons of retinal ganglion cells are insulted in the optic nerve early in DBA/2J glaucoma. J Cell Biol. 2007;179(7):1523-37.

38. Howell GR, Soto I, Zhu X, Ryan M, Macalinao DG, Sousa GL, et al. Radiation treatment inhibits monocyte entry into the optic nerve head and prevents neuronal damage in a mouse model of glaucoma. J Clin Invest. 2012;122(4):1246-61.

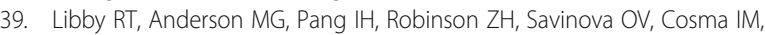
et al. Inherited glaucoma in DBA/2J mice: pertinent disease features for studying the neurodegeneration. Vis Neurosci. 2005;22(5):637-48.

40. Libby RT, Li Y, Savinova OV, Barter J, Smith RS, Nickells RW, et al. Susceptibility to neurodegeneration in a glaucoma is modified by Bax gene dosage. PLoS Genet. 2005;1(1):17-26.

41. Chou TH, Bohorquez J, Toft-Nielsen J, Ozdamar O, Porciatti V. Robust mouse pattern electroretinograms derived simultaneously from each eye using a common snout electrode. Invest Ophthalmol Vis Sci. 2014;55(4):2469-75.

42. Kim D, Pertea G, Trapnell C, Pimentel H, Kelley R, Salzberg SL. TopHat2: accurate alignment of transcriptomes in the presence of insertions, deletions and gene fusions. Genome Biol. 2013:14(4):R36.

43. Anders S, Pyl PT, Huber W. HTSeq--a Python framework to work with highthroughput sequencing data. Bioinformatics. 2015;31(2):166-9.

44. Robinson MD, McCarthy DJ, Smyth GK. edgeR: a Bioconductor package for differential expression analysis of digital gene expression data. Bioinformatics. 2010;26(1):139-40.

45. Mo JS, Anderson MG, Gregory M, Smith RS, Savinova OV, Serreze DV, et al. By altering ocular immune privilege, bone marrow-derived cells pathogenically contribute to DBA/2J pigmentary glaucoma. J Exp Med. 2003;197(10):1335-44.

46. Anderson MG, Nair KS, Amonoo LA, Mehalow A, Trantow CM, Masli S, et al. GpnmbR150X allele must be present in bone marrow derived cells to mediate DBA/2J glaucoma. BMC Genet. 2008;9:30.
47. Porciatti $V$, Saleh $M$, Nagaraju M. The pattern electroretinogram as a tool to monitor progressive retinal ganglion cell dysfunction in the DBA/2J mouse model of glaucoma. Invest Ophthalmol Vis Sci. 2007;48(2):745-51.

48. Nagaraju M, Saleh M, Porciatti V. IOP-dependent retinal ganglion cell dysfunction in glaucomatous DBA/2J mice. Invest Ophthalmol Vis Sci. 2007; 48(10):4573-9.

49. Howell GR, Walton DO, King BL, Libby RT, John SW. Datgan, a reusable software system for facile interrogation and visualization of complex transcription profiling data. BMC Genomics. 2011;12:429.

50. Vanlandewijck M, He L, Mae MA, Andrae J, Ando K, Del Gaudio F, et al. A molecular atlas of cell types and zonation in the brain vasculature. Nature. 2018;554(7693):475-80

51. He L, Vanlandewijck M, Mae MA, Andrae J, Ando K, Del Gaudio F, et al. Single-cell RNA sequencing of mouse brain and lung vascular and vesselassociated cell types. Sci Data. 2018:5:180160.

52. Zhang Y, Chen K, Sloan SA, Bennett ML, Scholze AR, O'Keeffe S, et al. An RNA-sequencing transcriptome and splicing database of glia, neurons, and vascular cells of the cerebral cortex. J Neurosci. 2014;34(36):11929-47.

53. Keren-Shaul H, Spinrad A, Weiner A, Matcovitch-Natan O, Dvir-Szternfeld R, Ulland TK, et al. A Unique microglia type associated with restricting development of Alzheimer's disease. Cell. 2017;169(7):1276-90 e17.

54. Hammond TR, Dufort C, Dissing-Olesen L, Giera S, Young A, Wysoker A, et al. Single-cell RNA Sequencing of microglia throughout the mouse lifespan and in the injured brain reveals complex cell-state changes. Immunity. 2019;50(1):253-71 e6.

55. Williams PA, Braine CE, Kizhatil K, Foxworth NE, Tolman NG, Harder JM, et al. Inhibition of monocyte-like cell extravasation protects from neurodegeneration in DBA/2J glaucoma. Mol Neurodegener. 2019;14(1):6.

56. Tribble JR, Harder JM, Williams PA, John SWM. Ocular hypertension suppresses homeostatic gene expression in optic nerve head microglia of DBA/2 J mice. Mol Brain. 2020;13(1):81.

57. Williams PA, Braine CE, Foxworth NE, Cochran KE, John SWM. GlyCAM1 negatively regulates monocyte entry into the optic nerve head and contributes to radiation-based protection in glaucoma. J Neuroinflammation. 2017;14(1):93

58. Carpanini SM, Torvell M, Morgan BP. Therapeutic inhibition of the complement system in diseases of the central nervous system. Front Immunol. 2019;10:362.

59. Kim YU, Kinoshita T, Molina H, Hourcade D, Seya T, Wagner LM, et al. Mouse complement regulatory protein Crry/p65 uses the specific mechanisms of both human decay-accelerating factor and membrane cofactor protein. J Exp Med. 1995;181(1):151-9.

60. Fonseca MI, Chu SH, Hernandez MX, Fang MJ, Modarresi L, Selvan P, et al. Cell-specific deletion of C1qa identifies microglia as the dominant source of C1q in mouse brain. J Neuroinflammation. 2017;14(1):48.

61. Fraser DA, Pisalyaput K, Tenner AJ. C1q enhances microglial clearance of apoptotic neurons and neuronal blebs, and modulates subsequent inflammatory cytokine production. J Neurochem. 2010:112(3):733-43.

62. Colonna L, Parry GC, Panicker S, Elkon KB. Uncoupling complement C1s activation from $\mathrm{Clq}$ binding in apoptotic cell phagocytosis and immunosuppressive capacity. Clin Immunol. 2016;163:84-90.

63. Stevens B, Allen NJ, Vazquez LE, Howell GR, Christopherson KS, Nouri N, et al. The classical complement cascade mediates CNS synapse elimination. Cell. 2007;131(6):1164-78.

64. El Gaamouch F, Audrain M, Lin WJ, Beckmann N, Jiang C, Hariharan S, et al. VGF-derived peptide TLQP-21 modulates microglial function through C3aR1 signaling pathways and reduces neuropathology in 5xFAD mice. Mol Neurodegener. 2020;15(1):4.

65. Wang Y, Sun SN, Liu Q, Yu YY, Guo J, Wang K, et al. Autocrine complement inhibits IL10-dependent T-cell-mediated antitumor immunity to promote tumor progression. Cancer Discov. 2016:6(9):1022-35.

66. Laffer B, Bauer D, Wasmuth S, Busch M, Jalilvand TV, Thanos S, et al. Loss of IL-10 promotes differentiation of microglia to a M1 phenotype. Front Cell Neurosci. 2019:13:430.

67. Liddelow SA, Guttenplan KA, Clarke LE, Bennett FC, Bohlen CJ, Schirmer L, et al. Neurotoxic reactive astrocytes are induced by activated microglia. Nature. 2017;541(7638):481-7.

\section{Publisher's Note}

Springer Nature remains neutral with regard to jurisdictional claims in published maps and institutional affiliations. 